\title{
Inheritance of reduced Varroa mite reproductive success in reciprocal crosses of mite-resistant and mite-susceptible honey bees (Apis mellifera)
}

\author{
Barbara Locke \\ Department of Ecology, Swedish University of Agricultural Sciences, PO Box 7044, 750 07, Uppsala, Sweden
}

Received 31 January 2015 - Revised 19 August 2015 - Accepted 21 October 2015

\begin{abstract}
A well-documented population of honey bees on Gotland, Sweden is resistant to Varroa destructor mites and is able in some way to reduce the mite's reproductive success. The aim of this study was to determine the genetic and maternal contribution to the inheritance of the reduced mite reproductive success trait in this population. Four genotypic groups of colonies were established by crossing the mite-resistant population of Gotland with a mitesusceptible population in Uppsala, Sweden, through artificial insemination of reared queens with drone semen. All the colonies in groups with a genetic origin from the resistant population expressed reduced mite reproductive success regardless if the genetic origin was maternal, paternal or both, and no statistical differences were observed between the reciprocal crosses. These results strongly imply a dominant genetic component to the trait's inheritance, as opposed to maternal effects or epigenetic mechanisms, and that the trait can be easily produced through selective breeding using the mite-resistant Gotland bee stock.
\end{abstract}

Varroa destructor / mite resistance / breeding / mite reproduction

\section{INTRODUCTION}

Improving the disease resistance of beneficial animals is a common goal of many breeding programmes. For the western honey bee (Apis mellifera), this goal is of increasing importance since honey bees suffer from a wide variety of parasites and pathogens (e.g. mites, microsporidians, fungi, bacteria and viruses). Disease is a main driver behind the devastating global honey bee colony losses (Neumann and Carreck 2010), warranting the many efforts directed to breeding disease resistance in honey bees.

Among the many organisms that plague honey bees, the ectoparasitic mite-Varroa

Corresponding author: B. Locke, barbara.locke@slu.se Manuscript editor: Yves Le Conte destructor - is by far the most damaging. The most injurious effect of the mite is caused by its function as a vector of honey bee viruses (most notably deformed wing virus) eventually causing a viral epidemic that will ultimately kill the bee colony (Nordström et al. 1999; Martin 2001; Chen et al. 2006; Boecking and Genersch 2008; Gisder et al. 2009). Beekeepers are required to use regular Varroa mite control management to avoid colony death. Control methods, however, can often have adverse effects on bees (Haarmann et al. 2002; Locke et al. 2012a), leave residues in honey (Wallner 1999) and can be expensive for beekeepers. Further, mites can develop resistance towards the chemical treatments rendering their affect useless (Sammataro et al. 2005). For these reasons, a more promising long-term solution to the Varroa mite problem is in selecting for miteresistant lines of honey bees. Well-known breeding programmes that have focused on reducing 
colony mite infestation include Varroa - sensitive hygienic bees (VSH), Minnesota hygienic bees $(\mathrm{MH})$, Russian bees (reviewed in Rinderer et al. 2010) and the Kefuss strain in France (reviewed in Büchler et al. 2010).

Disease is also an important factor driving natural selection. Apis mellifera populations in South America and Africa are resistant to Varroa mites and do not need mite control to stay alive (Rosnekranz 1999; Allsopp 2006). Although most honey bees in Europe and North America are susceptible to Varroa, a few isolated honey bee populations have survived Varroa mite infestation despite a lack of mite control treatments for exceptionally many years (>over 10 years; e.g. Fries et al. 2006; Seeley 2007; Le Conte et al. 2007). Perhaps, the most in-depth studied population of mite-resistant European honey bee colonies is on the Island of Gotland, Sweden (Fries et al. 2003, 2006; Fries and Bommarco 2007; Behrens et al. 2011; Locke and Fries 2011; Locke et al. 2014). One suggestion to explain this population's long-term survival is that adaptive mite resistance has resulted from exposure to natural mite infestation pressures due to a lack of apicultural management.

Reduced mite reproductive success has been documented as a colony-level mite-resistant trait in the Gotland population (Locke and Fries 2011) as well as in a similar but unrelated long-term mite-surviving population in Avignon, France (Locke et al. 2012b). Although it is still not known how the bees influence the mite's ability to reproduce in these bee populations mentioned, the trait is none-the-less observable as an individual mother mite's ability or inability to produce a viable female offspring that will survive after bee pupal eclosion. The trait is considered a colony-level trait (expressed as a frequency of successfully reproducing mother mites within a colony) since it has an effect on the colony's fitness by limiting the mite population growth and consequently also the subsequent viral epidemic transmitted by the mite. Accordingly, it is an important trait and is at least partly responsible for the Gotland population's survival. There have been few studies on the genetics of the inheritance of this trait, and so its potential for honey bee breeding programmes is relatively unknown.
The aim of this study was to determine the genetic and maternal contribution to the inheritance of the reduced mite reproductive success trait from the Gotland population. This was done by using reciprocal hybrids of mite-resistant bees from the island of Gotland, Sweden and mite-susceptible bees from Uppsala, Sweden. From a practical perspective, the aim was to determine the potential usefulness of this trait and the Gotland mite-resistant genetic stock for breeding Varroa mite resistance.

\section{MATERIALS AND METHODS}

(1) the mite-resistant population of honey bee colonies on the island of Gotland, Sweden that has survived with mites for over a decade without control treatments and (2) a mite-susceptible group of colonies from Uppsala, Sweden that has been under regular beekeeping management. Seven colonies from the Gotland population and ten colonies from the Uppsala population served as parental sources for the crosses. Queens were reared and artificially inseminated with semen collected from single drones to produce unique crosses. None of the queens were mated with their brothers since the sperm and queens were selected from different colonies. Besides this control, the crosses were random. The following genotypic groups were obtained with four colonies in each group (queen origin $\times$ drone origin): Gotland $\times$ Gotland $(\mathrm{GG})$, Gotland $\times$ Uppsala $(\mathrm{GU})$, Uppsala $\times$ Gotland $(\mathrm{UG})$ and Uppsala $\times$ Uppsala (UU). Environmental variation was limited between colonies by introducing the inseminated queens randomly into 10 -frame colonies with similar bee population strength and by keeping all colonies in the same apiary in Uppsala, Sweden. An 8-week waiting period allowed a turnover of the bee population within the colonies so that at the time the observations on mite reproduction were made, most if not all of the adult bees would be offspring of the introduced inseminated queen. The colonies were known to have Varroa mites, but the exact mite infestation rates were only determined after the 8 -week waiting period.

Mite reproduction occurs in the brood cells of pupating bees. Successful mite reproduction is 
defined here as the production of at least one viable, mated female offspring before the developing bee pupae emerges as an adult. A detailed description of the methods for evaluating colonylevel successful mite reproduction can be found in Locke and Fries (2011). In short, worker bee pupae at least older than approximately $190 \mathrm{~h}$ (brown eyes and yellow body stage; Martin 1994) were carefully removed from the frame. The developmental stage of each pupa was recorded based on the appearance description given by Martin (1994). Complete mite families (mother mite, eggs, male, nymphs, etc.) from cells infested with a single mother mite were removed using a fine brush, examined with a stereo-microscope and recorded. The presence and age of mite offspring in relation to pupal age were contrasted to determine if at least one viable daughter would survive past pupal eclosion. Around 30 single infested cells per colony were examined for each colony to establish a colony-level rate of successfully reproducing mites within the colony (Figure 1). A mother mite that lays no eggs, lays only one egg, produces no male offspring, has dead offspring, or begins egg-laying too late for the daughters to mature in time in relation to larval development, will not contribute progeny to the mite population and would be classified as unsuccessful reproduction (Martin 1994; Harbo and Harris 1999; Locke and Fries 2011).

An analysis of variance (ANOVA) was used to determine if mite reproductive success rates differed among the different genotypic groups and to determine if differences were dependent on genetic origin, maternal origin or paternal origin. Student $t$ tests were performed to compare mite reproductive success rates between the different genotypic groups.

\section{RESULTS}

Colony-level Varroa mite reproductive success differed significantly between the genotypic groups in this study $\left(F_{3,12}=16.51, P<0.0001\right)$. The proportions of successfully reproducing mites in each colony in the four genotypic groups are presented in Figure 1. All genotypic groups with a Gotland (mite-surviving) genetic background had significantly reduced mite reproductive success compared to the pure crosses from Uppsala $\left(F_{1,14}=38.48\right.$, $P<0.0001$; Figure 1). This included the reciprocal hybrid crosses between the populations, independent of whether the queen or the sperm came from the Gotland population, i.e. no significant maternal $\left(F_{1,14}=4.49, P=0.0524\right)$ or paternal $\left(F_{1,14}=1.44\right.$, $P=0.2493$ ) effects were observed.

The hybrid group with Gotland queen origin and Uppsala drone origin (GU) had the lowest average mite reproductive success (mean $=0.43, \sigma \pm 0.05$; Figure 1). However, no significant differences were observed between the GU group and the reciprocal hybrid group, with Gotland drone origin (UG; $P=0.47)$. The pure strain crosses with Uppsala origin (UU) had the highest mite reproductive success (mean $=0.85, \sigma \pm 0.02$; Figure 1), which was significantly higher than all other genotypic groups (GG: $P=0.0003$; GU: $P=0.0009$; UG: $P=0.017$ ).

The genotypic group of colonies with pure Gotland crosses (GG) was not significantly different from the hybrid group with Gotland drone origin (UG; $P=0.424$ ) or from the hybrid group with Gotland queen origin (GU; $P=0.052$ ).

\section{DISCUSSION}

A notable reduced mite reproductive success was expressed by all colonies in the three genotypic groups containing genetic origin from the mite-surviving Gotland population, regardless if the queen was from a pure cross (GG), had only a maternal Gotland origin (GU) or only a paternal Gotland origin(UG). This result strongly suggests that a genetic component is responsible for the trait's inheritance. Further, these results demonstrate a degree of dominance for the trait in the Gotland population, which raises the possibility of success at breeding mite resistance using this trait as a breeding tool.

Behrens et al. (2011) found three quantitative trait loci (QTL) that interfered with Varroa reproduction when screening drones from Gotland hybrid honey bee colonies and that these QTL had a non-additive epistasis effect on the expression of this trait. The epistasis effect means that the expression of one gene depends on the presence of one or more modifier genes. Behrens et al. (2011) suggested that this would cause complications for selective breeding from this Gotland population. 


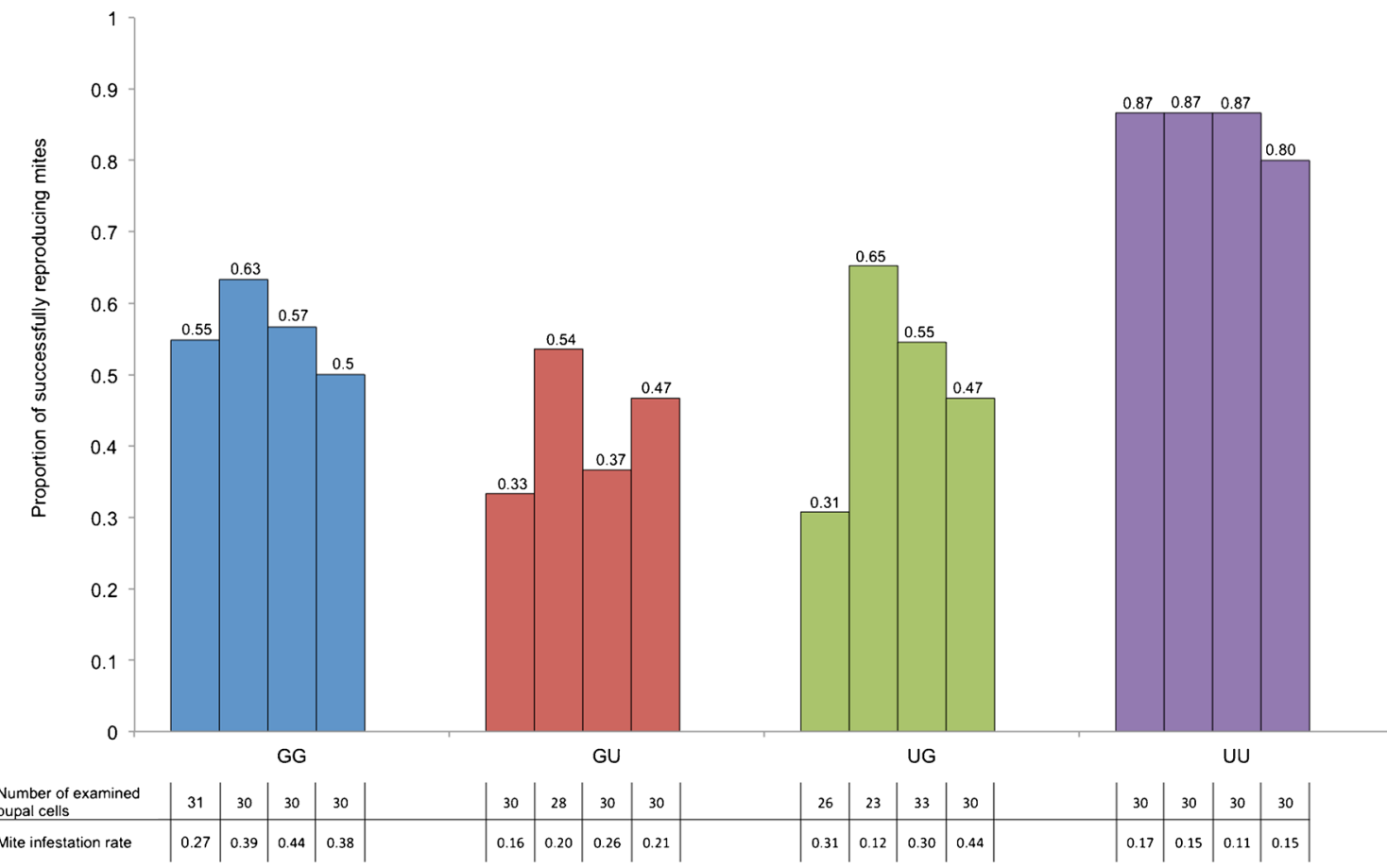

Figure 1. The histogram presents the proportion of successfully reproducing Varroa mites in each colony within the different genotypic groups: Gotland $\times$ Gotland pure crosses (GG: mean $=0.56 ; \sigma \pm 0.03$ ), Gotland $\times$ Uppsala hybrid crosses (GU: mean $=0.43 ; \sigma \pm 0.05$ ), Uppsala $\times$ Gotland hybrid crosses (UG: mean $=0.49 ; \sigma \pm 0.07$ ), and Uppsala $\times$ Uppsala pure crosses (UU: mean $=0.85 ; \sigma \pm 0.02$ ). Below the histogram, the number of examined pupal cells and mite infestation rates are presented corresponding to each colony.

However, the results of the present study suggest that mite-resistant breeding for reduced Varroa mite reproductive success having a dominant simple genetic inheritance might not be so complicated, even with an epistasis effect on the genes responsible for the traits expression.

As for the mode of inheritance, the expression of reduced mite reproductive success in the genotypic group of colonies with only a paternal origin from the mite-resistant Gotland population is strongly indicative of a dominant genetic effect influencing its expression, as opposed to maternal effects or epigenetic mechanisms. The lack of difference between the reciprocal crosses in this study demonstrates the lack of a maternal effect on the expression of this trait, even if the maternal group had the lowest average mite reproductive success. Both maternal effects and paternal effects have previously been demonstrated to influence the expression of honey bee behaviours such as hygienic behaviour (Unger and Guzmán-Novoa
2010) and defensive behaviour (Guzmán-Novoa et al. 2005), respectively. However, since the trait examined in this study was expressed almost equally in colonies with paternal or maternal origin from the Gotland population, these options can be ruled out as the mode of inheritance for this trait.

Difficulties with low survival and acceptance of single-drone inseminated queens were experienced in this experiment. Although more replicates would have been desirable, the low variation within each genetic group produced strong statistical effects enough to support the inferences made here. The within-group results of this study are further supported by consistencies with mite reproductive success rates seen in previous studies in mite-resistant and mite-susceptible honey bees populations (Locke and Fries 2011; Locke et al. 2012b).

Breeding programmes aimed at selecting and enhancing the expression of colony-level traits such as hygienic behaviour (Spivak and Reuter 
2001) and Varroa $-s$ ensitive hygienic behaviour (VSH; Harbo and Harris 2005; 2009) have been successful at reducing the mite population growth rate in a colony. Further, breeding programmes using a mite-tolerant Russian stock have had similar positive results (Rinderer et al. 2001). The genetic stock from the Gotland mite-resistant population, having evolved through natural selection as opposed to artificial selection, may be a promising direction for mite resistance breeding or a valuable addition to already established breeding programmes as mentioned above. Although before committing to a large-scale breeding programme, repeating this study with a larger sample size than what was available for this experiment would be beneficial.

The exact mechanism causing this trait remains unknown. It has previously been suggested to be a characteristic of the bee rather than of the mite after the work of Fries and Bommarco (2007) demonstrated that the Gotland bee colonies had lower mite growth rates regardless of where the mites came from or the environment where the bees were placed. Chemical compounds of the developing bee pupa are responsible for initiating the mite to begin egg laying (Garrido and Rosenkranz 2003; Milani et al. 2004; Frey et al. 2013), and one hypothesis is that the bee pupae of the Gotland population have an altered chemical ecology that interrupts the reproductive system of the mite (Locke et al. 2012b). VSH behaviour could also potentially be involved as a mechanism for this trait in the Gotland population. VSH bees remove mite-infested brood, specifically successfully reproducing mites, which leaves the remaining mite population to appear to have a larger proportion of infertile mites than in reality (reviewed in Rinderer et al. 2010). Determining the mechanism of this reduced mite reproductive success trait in the Gotland population is a current research direction including determining if the trait is regulated by pupal volatiles or adult bee behaviours such as VSH.

This study demonstrates a clear dominant genetic effect on the inheritance of reduced mite reproductive success in the Gotland honey bee population. Further studies similar to this one could be performed on other populations of bees that express this trait to determine whether or not the results in this study are due to a population specific effect of the Gotland mite-surviving bees. Measuring quantitative heritability in this population could also be a future goal. From a practical perspective, a next step could be to establish a selective breeding programme using reduced mite reproduction as a tool for enhancing colony mite resistance in commercial apiculture. However, measuring this trait is tedious work and a more realistic first approach may be to introduce the Gotland genetic stock to an already established mite-resistant breeding line such as VSH bees to try to enhance colony-level mite resistance from multiple angles.

\section{ACKNOWLEDGMENTS}

Gratitude is expressed to Bert Thrybom for his help with queen insemination and to Drew Katz and Mia Bergström for their field assistance. Åke Lyberg is thanked for maintaining the population of mitesurviving bees on Gotland. Ane Laugen, Ingemar Fries and Joachim de Miranda are thanked for valuable input on this manuscript. Financial support was provided by The Swedish Research Council Formas, diarienr. 20121060. Financial support for maintaining the miteresistant bee population on Gotland is provided by Jordbruksverket.

Transmission du succès reproductif réduit de l'acarien Varroa dans des croisements réciproques entre abeilles (Apis mellifera) résistantes et abeilles sensibles à l'acarien

Varroa destructor / élevage / reproduction / résistance aux acariens

Vererbung eines reduzierten VarroaReproduktionserfolges nach reziproken Kreuzungen von varroaresistenten und nicht-resistenten Honigbienen (Apis mellifera)

Varroa destructor / Varroaresistenz / Züchtung / Varroareproduktion

\section{REFERENCES}

Allsopp, M. (2006) Analysis of Varroa destructor infestation of southern African honey bee populations. M.S. Thesis, University of Pretoria, Pretoria, South Africa 
Behrens, D., Huang, Q., Geßner, C., Rosenkranz, P., Frey, E., Locke, B., Moritz, R.F.A., Kraus, F.B. (2011) Three QTL in the honey bee Apis mellifera L. suppress reproduction of the parasitic mite Varroa destructor. Ecol. Evol. 1, 451-458

Boecking, O., Genersch, E. (2008) Varroosis - the ongoing crisis in beekeeping. J. Consum. Protect Food Saf. 3, 221-228

Büchler, R., Berg, S., Le Conte, Y. (2010) Breeding for resistance to Varroa destructor in Europe. Apidologie 41, 393-408

Chen, Y.P., Evans, J.D., Feldlaufer, M.F. (2006) Horizontal and vertical transmission of viruses in the honey bee, Apis mellifera . J. Invertebr. Pathol. 92, 152-159

Frey, E., Odemer, R., Blum, T., Rosenkranz, P. (2013) Activation and interruption of the reproduction of Varroa destructor is triggered by host signals (Apis mellifera ). J. Invertebr. Pathol. 113, 56-62

Fries, I., Bommarco, R. (2007) Possible host-parasite adaptations in honey bees infested by Varroa destructor mites. Apidologie 38, 525-533

Fries, I., Hansen, H., Imdorf, A., Rosenkranz, P. (2003) Swarming in honey bees (Apis mellifera) and Varroa destructor population development in Sweden. Apidologie 34, 389-397

Fries, I., Imdorf, A., Rosenkranz, P. (2006) Survival of mite infested (Varroa destructor) honey bee (Apis mellifera) colonies in a Nordic climate. Apidologie 37, 1-7

Garrido, C., Rosenkranz, P. (2003) The reproductive program of femal Varroa destructor mites is triggered by its host. Apis mellifera. Apidologie 35 (419), 430

Gisder, S., Aumeier, P., Genersch, E. (2009) Deformed wing virus: replication and viral load in mites (Varroa destructor ). J. Gen. Virol. 90, 463-467

Guzmán-Novoa, E., Hunt, G.J., Page Jr., R.E., UribeRubio, J.L., Prieto-Merlos, D., Becerra-Guzman, F. (2005) Paternal effects on the defensive behaviour of honey bees. J. Hered. 96, 376-380

Haarmann, T., Spivak, M., Weaver, D., Weaver, B., Glenn, T. (2002) Effects of fluvalinate and coumaphos on queen honey bees (Hymenoptera: Apidae) in two commercial queen rearing operations. J. Econ. Entomol. 95, 28-35

Harbo, J.R., Harris, J.W. (1999) Selecting honey bees for resistance to Varroa jacobsoni . Apidologie 30, 183-196

Harbo, J.R., Harris, J.W. (2005) Suppressed mite reproduction explained by the behaviour of adult bees. J. Apic. Res. 44, 21-23

Harbo, J.R., Harris, J.W. (2009) Responses to Varroa by honey bees with different levels of Varroa sensitive hygiene. J. Apic. Res. 48, 156-161

Le Conte, Y., de Vaublanc, G., Crauser, D., Jeanne, F., Rousselle, J.-C., Bécard, J.-M. (2007) Honey bee colonies that have survived Varroa destructor. Apidologie 38, 566-572

Locke, B., Fries, I. (2011) Characteristics of honey bee colonies (Apis mellifera) in Sweden surviving Varroa destructor infestation. Apidologie 42, 533-542
Locke, B., Forsgren, E., Fries, I., de Mirada, J.R. (2012a) Acaricide treatment affects viral dynamics in Varroa destructor-infested honey bee colonies via both host physiology and mite control. Appl. Environ. Microbiol. 78, 227-235

Locke, B., Le Conte, Y., Crauser, D., Fries, I. (2012b) Host adaptations reduce the reproductive success of Varroa destructor in two distinct European honey bee populations. Ecol. Evol. 2, 1144-1150

Locke, B., Forsgren, E., de Miranda, J.R. (2014) Increased tolerance and resistance to virus infection: a possible factor in the survival of Varroa destructor resistant honey bees (Apis mellifera). PLoS ONE 9(6), e99998. doi:10.1371/journal.pone.0099998

Martin, S.J. (1994) Ontogenesis of the mite Varroa jacobsoni Oud. in worker brood of the honey bee Apis mellifera L. under natural conditions. Exp. Appl. Acarol. 18, 87-100

Martin, S.J. (2001) The role of Varroa and viral pathogens in the collapse of honey bee colonies: A modelling approach. J. Appl. Ecol. 38, 1082-1093

Milani, N., Della, V.G., Nazzi, F. (2004) (Z)-8-Heptadecene reduces the reproduction of Varroa destructor in brood cells. Apidologie 35, 2654-274

Neumann, P., Carreck, C. (2010) Honey bee colony losses: a global perspective. J. Apic. Res. 49, 1-6

Nordström, S., Fries, I., Aarhus, A., Hansen, H., Korpela, S. (1999) Virus infections in Nordic honey bee colonies with no, low or severe Varroa jacobsoni infestations. Apidologie 30, 475-484

Rinderer, T., de Guzman, L.I., Delatte, G.T., Stelzer, J.A., Lancaster, V.A., Kuznetsov, V., Beaman, L., Watts, R., Harris, J.W. (2001) Resistance to the parasitic mite Varroa destructor in honey bees from far-eastern Russia. Apidologie 32, 381-394

Rinderer, T., Harris, J.W., Hunt, G.J., de Guzman, L.I. (2010) Breeding for resistanceto Varroa destructor in North America. Apidologie 41, 409-424

Rosnekranz, P. (1999) Honey bee (Apis mellifera L.) tolerance to Varroa jacobsoni Oud. in South America. Apidologie 30, 159-172

Sammataro, D., Untalan, P., Guerrero, F., Finley, J. (2005) The resistance of Varroa mites (Acari: Varroidae) to acaricides and the presence of esterase. Int. J. Acarol. 31, 67-74

Seeley, T.D. (2007) Honey bees of the Arnot Forest: a population of feral colonies persisting with Varroa destructor in the northeastern United States. Apidologie 38, 19-29

Spivak, M., Reuter, G.S. (2001) Varroa jacobsoni infestation in untreated honey bee (Hymenoptera: Apidae) colonies selected for hygienic behaviour. J. Econ. Entomol. 94, 326-331

Unger, P., Guzmán-Novoa, E. (2010) Maternal effects on the hygienic behavior of Russian x Ontario hybrid honey bees (Apis mellifera L.). J Heredity 10, 91-96

Wallner, K. (1999) Varroacides and their residues in bee products. Apidologie 30, 235-248 